\title{
Feminist epistemologies in research: mini review
}

\begin{abstract}
Broadly, Feminist epistemologies in research aim to challenge conventional assumptions of positivist empiricism. These authors argue that an everyday social interaction, that is the 'stuff' that makes up the object of research, is in reality messy and cannot be conveyed through quantifiable indicators. This mini review is based on a selected list of authors who apply feminist approaches. I will explore how these writings relate to one another, and show that 'feminists' are marked by irreducible differences which should be embraced for a productive scholarly debate.
\end{abstract}

Keywords: readings, observations, propositions, epistemology, feminist approaches, interdependent, relationships
Volume 3 Issue 4 - 2019

\author{
Lynn NgYu Ling \\ Department of Political Science, University of Victoria, Canada
}

Correspondence: Lynn Ng Yu Ling, Department of Political Science, University of Victoria, 3800 Finnerty Rd,Victoria, BCV8P 5C2, Canada, Tel + I 778-584-9178, Email lynnngyuling@uvic.ca

Received: April 29, 2019 | Published: July 22, 2019

\section{Mini review}

This review essay is informed by readings around Feminist Epistemologies. Broadly, conventional positivist epistemology is concerned with general accounts or theories of knowledge, based on assumptions that general propositions of social phenomena can be uncovered. ${ }^{1}$ Accurate information derives from "sensory observations in ideal observation conditions" where detached, neutral observers perceive transparent objects of knowledge. ${ }^{2}$ Adding nuance to the Gender Debate, feminist approaches highlight the messiness of social interaction, such that information and knowledge arises organically from interdependent relationships with others. ${ }^{3}$ Following this, I identify broader issues of controversy within feminist approaches and possible implications for research and policymaking.

It must be noted that given the space constraints, this essay is more concerned with exploring ideological ambiguities and discrepancies within feminist approaches rather than devoting itself to issues of tools and methods. This in no way implies that the latter is of inferior priority, however considering the author's limited fieldwork experience, it is more fruitful to engage in issues of epistemological grounding instead of suggesting procedures for research. Ultimately, this essay hopes to demonstrate that for a productive feminist politics, the current field would benefit from consulting resources for fostering 'openness': possibilities of mutual receptivity in recognising difference. ${ }^{4}$ In this sense, common narratives of Global Sisterhood must be treated with caution, because 'women' are not a homogenous category with a singular experience of gender discrimination. ${ }^{5}$ Women are differentially affected depending on the myriad of social identities they inhabit, most notably Nationality, Class and Race. ${ }^{6}$

Especially prominent in the interaction between feminist thinkers is a long-lasting inability to agree on the status/possibility of Objectivity, conceived as accurate information that can be obtained and communicated in the Real World. ${ }^{7}$ That is, "reality can be observed, measured and ascertained by an objective researcher... there are social laws or social facts that can be found...". ${ }^{8}$ In calling for a 'constructivist reorientation', Code ${ }^{2}$ retains faith in "a realistic commitment to achieving empirical adequacy", hence her conviction that "Objectivity requires taking subjectivity into account". However, Scott ${ }^{9}$ among others express skepticism around the notion of codifying knowledge, especially if we consider the realm of experiential knowledge. Here the danger of language systems (words) as a communicable medium of observable phenomena (things in the world) is highlighted, revealing a visibility bias in traditional Western metaphysical thought. ${ }^{10}$ In this framework, seeing is knowing:
"Knowledge is gained through vision; vision is a direct apprehension of a world of transparent objects...the visible is privileged; writing is then put at its service". ${ }^{9}$ Similarly, on the validity of Indian historiography, Spivak ${ }^{11}$ echoes concerns around the taken-forgranted criteria of the English autobiography: literary representations of one's public and private lives. Thus one neglects the contestations around accessibility to educational/publishing resources, and crucially even among privileged literates, social expectations around the acceptability of displaying one's private life 'out there'. Following this, Scott ${ }^{9}$ recognises the 'idiosyncratic' and unpredictable fluidity of categories like 'experience', which itself is perhaps a variety of emotion/feeling that has to be communicated as a conceptual category. Hawkesworth ${ }^{12}$ too highlights the contradictions between feminist empiricism, feminist standpoint theories and feminist postmodernism. While the first adheres to positivist convictions by advocating for the 'control of subjectivity' (masculine biases) through disciplined/ rigorous exercise of systematic observation, the second questions positivist versions of truth. Instead it postulates that truth has been distorted by the social positions of (masculine) observers, hence the ideological perspectives stemming from women's (oppressed) social positions should be privileged. That said, the first two seem convinced that an objective, discoverable truth exists, while the latter would hesitate to accept that $a$ truth is possible. In light of awkward tensions surrounding Objectivity, perhaps we can refer back to feminist epistemology's outset: all knowledge is power, hence regardless of methodological outlook and particular methods, research never ceases to be an expression of one's political awareness. ${ }^{13}$ Following up on this emphasis on 'critical reflexivity', there is potential for more mutual recognition of one another's versions of feminist postulations through 'empathetic cooperation'. This process entails 'positional slippage' when one apprehends texts that seem alien/unsettling to one's habitual thought, also recognising that at stake is a difficulty of comprehension more than accurate ways of knowing 'right' from 'wrong'. ${ }^{14}$ To illustrate this possibility, exploring the dialogue between feminist thinkers on 'Gender' is useful.

The lack of consensus around the applicability/relevance of 'Gender' to contexts and societies worldwide is also an evident tension for the over-romanticised feminist 'community'. The usage of 'Gender' as a rallying point in not only but especially Anglophone academic circles has unfortunately resulted in exclusionary politics. 'Gender' as understood in dominant English-based institutions broadly connotes a social force acting on people's behavior., ${ }^{4,11}$ That is, individuals behave according to socialised conventions ingrained since foundational childhood years, of how men and women as categories of social beings wield comparative advantage in respective 
areas. Overwhelmingly, gendered norms rely on the 'public man' 'private woman' dichotomy. Men possess more aggressive attributes tailored for a Social Darwinist atmosphere of competition 'out there' in public. Women naturally incline towards emotional/ 'motherly' tendencies that detract from objective rationality, hence are better suited for the private domestic realm. ${ }^{6}$ In a Capitalist context, work is only recognised when it contributes directly to processes of accumulation, and hence women's domestic duties are not considered 'real' work.

Following an acknowledgement of the above mechanism of gendered marginalization, within feminist literature two broad strands (continuum) of 'resistance' or reformulation towards 'Gender' can be identified. The first is regarding how 'Gender' operates in women's lives, while the second goes further to reflect on the utility of 'Gender' itself as an analytical tool when applied to respective contexts. In the first instance, diverse perspectives emerge from women situated in different positions, especially considering individual racial classification, socioeconomic status and household circumstances. ${ }^{15}$ Intersectionality serves as a useful analytical framework to illustrate how 'women' cease to be a unitary category with common experiences of marginalization as the 'global sisterhood' narrative propounds. ${ }^{5}$ In thought-provoking discussions of the experiences of battering and rape among women of color in the United States, Kimberle Crenshaw elucidates the heightened salience of racism that contributes to more profound and multi-dimensional discrimination relative to white women. Albeit not totally, white women enjoy greater likelihood of securing battering/rape assistance. ${ }^{16}$ Women of color often confront hostile police authorities whom they would rather not risk contacting. English-centric institutional (structural) barriers are also highly relevant as some shelters require 'clients' to be English speaking, and have rejected (mostly) women of color for being unable to articulate their situation 'coherently' or 'intelligibly'. From these scenarios, one can postulate that 'Gender' oppresses both women but for the latter, institutional racism matters hugely.

Going further, postcolonial feminist thinkers have reflected on the utility of 'Gender' as an analytical tool. At stake is not simply the various ways that 'Gender' exerts its force, but whether it even works at all. Pondering about the representability of 'voiceconsciousness', Spivak ${ }^{11}$ illustrates the 'subaltern' figure who is unable to speak (with conventional tools of representation); even when she does, is substantially misheard as anecdotal interest instead of being taken seriously. Particularly of note is the intensity of 'invisibility' that is implied: national legislation and systems of redress, including those tailored for 'marginalized' sections, fail to provide tools of communication that accommodate the subaltern's 'birth circumstance'. ${ }^{11}$ Implicit here is a larger argument about ways of knowing that Anglophone institutions have largely been unable to access, not only because of the impossibility of technical translations of 'Gender', but also its losses in transposition. Her innovative discussion of the British abolition of widow sacrifice in 1829 revealed how British missionary registers were unable to envision alternative interpretations of the practice of sati (widow self-immolation) other than 'barbaric' Hindu culture. Overwhelmingly framed as a heroic endeavor of " white men save brown women from brown men", "one never encounters the testimony of the women's voice-consciousness". ${ }^{11}$ Instead British authorities expressed ridicule at the woman who 'actually wanted to die', thus it was a problem of 'unenlightened' women who could not even recognise their own oppression. However within the Dharmasastra (ancient Sankrit texts), there are cases of 'sanctioned suicide' where the performer is an agentic subject who comprehends the intensity of their action. Indeed, such death may be understood by the widow as "an exceptional signifier of her own desire" (Ibid: 96). British insistence on classifying sati as 'revolting' then vividly illustrates Jean-Francois Lyotard's notion of differend: the inaccessibility/untranslatability between modes of discourses in a dispute where there exists no common language of articulation for the 'wrong'. ${ }^{17}$ British insistence on the force of 'Gender' interpreted sati as 'punishment', without recognising that the composition of the female subject occupies the site of differend. Crucially, this does not mean supporting self-immolation, but rather recognising alternative ways of looking at this action. In non-English-speaking realms, perhaps the ontological framework of reading social behavior as implied by 'Gender' fails to resonate. ${ }^{9,18}$ Particularly worrying then is the disjuncture between scholar-activists and the women-participants of research, for feminist approaches informed by 'Gender' might not always constitute a conducive starting point for mutual engagement.

The above dilemma can be gleaned from research encounters which are open to a myriad of interpretative angles. Nazgol Bagheri hints at an underlying tension between 'Western' and 'other' feminisms, given that the former has been perceived as overly 'hostile' and exclusionary towards men especially when arguing for 'women-only' standpoints. Through incorporating stories about usages of public space in Tehran, we obtain more holistic understandings of Iranian women's sense of agency and feelings towards 'Gender'. These perspectives in Bagheri ${ }^{18}$ suggest that "Gender, by itself, does not offer an essential category or an independent social construct and it may be studied in regards to culture, class, race and sexuality (Italics mine)." Especially important for this essay is recognising that within this statement contains the continuum of feminist reformulations of 'Gender'. Crucial to note is that Bagheri ${ }^{18}$ reminder remains at the level of application and analysis, while adhering to the larger structural definition of a socialised 'Gender'. Similarly, recurrent studies on Intersectionality have often been obsessed with categorising experiences/feelings towards 'Gender' and ranking them for individuals, ${ }^{15}$ thus neglecting Crenshaw's ${ }^{16}$ painstaking reminder of "the need to account for multiple grounds of identity" in experiences of marginalization rather than privileging particular categories. Unfortunately, Gender, Race and Class has become somewhat of a compulsory universal triad that feminist work must engage with, on its normative terms. ${ }^{4}$ Still implicit is an acceptance of the apparent fact that sex connotes biology while 'Gender' is its socially constructed aspect. ${ }^{19,20}$ Yet there is potential within Bagheri ${ }^{18}$ for a deeper recognition of 'Gender' as itself an interpretative framework for relations between men and women. ${ }^{12}$ Spivak, ${ }^{22}$ also Scott, ${ }^{9}$ might show caution with starting research with an outset of looking for 'Gender', since that risks coercing participants into narratives of 'dependency', 'pain' and 'victimization', which indeed constitute 'points of attraction' to expectant researchers (and funding). ${ }^{21}$

Feminist demographic research often faces the above scenario, especially if well-intentioned researchers are convinced that "it is important to measure gender at all levels". ${ }^{8}$ This does not imply that Gender studies should be foreclosed, however Bar On, ${ }^{21}$ Scott $^{9}$ and Sundberg ${ }^{3}$ do hint at the dangers of 'epistemological violence', which from a postcolonial feminist perspective, connotes the symbolic power of manipulating a set of data to speak for and about others (often not favourably) when there exist a myriad of alternative interpretations ${ }^{11}$ In contrast to the 'urge to classify' other women as oppressed by 'Gender', Rose ${ }^{23}$ and Haraway's ${ }^{24}$ 'situated knowledges' remind us that a conducive feminist politics would aspire to "produce non-over generalizing knowledges that learn from other kinds of knowledges"; including that from language systems which do not contain an ontological framework like 'Gender' ${ }^{3}$ For example, it is not uncommon for Participatory Action Research (PAR) to impose a visibility bias; 'speaking up' is considered as evidence of women's agency. ${ }^{9}$ However the lack of public speaking can also indicate that women are weighing the 'costs of resistance' amidst an awareness of their community's social acceptance of women being vocal in public. ${ }^{25,26}$ If we recognise research as always political, ${ }^{13}$ then the 
inability to recognise 'silence' as also a form of agency and political expression/reaction also reflects the researcher's limited positionality.

To end on an encouraging note, it is worthy to note that none of the authors mentioned imply that their propositions deserve universal applicability. Informed by feminist epistemologies, collectively they show that ways of practicing 'feminist' are irreducible and always conflicted, hence is not a singular ' $\mathrm{I}$ '. ${ }^{21}$ To reiterate the importance of respecting the many voices within feminism, the research methods employed by researchers do not automatically signal their view of social phenomena, nor is there any necessary correlation between one's 'worldview' and research tools. ${ }^{12,27}$ Feminist empiricists may align with traditional views of scientific credibility and advocate for stronger rigor in deploying instruments of measurement, ${ }^{20}$ yet at the same time confer epistemological privilege to the perspectives of women who possess firsthand experience of struggle. ${ }^{10}$ Furthermore, another prominent theme is contentions over the status/possibility of Objectivity, also how “Gender' works (or the extent to which it works, if at all).

This essay is interested not so much in how to "measure" Gender, but more in highlighting the dearth of feminist work that explores the latter aspect of 'Gender' in terms of its ideological relevance to the people we are interested in helping. That is, do the people we study think of their own lives as marked by 'Gender' the way researchers conceptualize this term? Thus far, debates concentrate on the varieties of how 'Gender' manifests itself in visible outcomes, but more ideological resources are needed for unpacking this very conceptual category. What can "Gender" mean other than what we already believe it to be? Most of all, looking to the strength and resilience in the experiences of women who have been historically marginalized from knowledge production in the Anglophone Academy can help inspire us towards empathy and cooperation.

\section{Acknowledgments}

No.

\section{Conflicts of interest}

The author declares that there are no conflicts of interest.

\section{Funding}

None.

\section{References}

1. Moses JW, Knutsen TL. Ways of Knowing: Competing Methodologies in Social and Political Research. $2^{\text {nd }}$ edn. China: Palgrave Macmillan; 2012. $368 \mathrm{p}$

2. Code L. Taking Subjectivity into Account. In: Alcoff L, Potter E, editors Feminist Epistemologies. New York: Routledge; 1933. pp. 15-48.

3. Sundberg J. Looking for the critical geographer, or why bodies and geographies matter to the emergence of critical geographies of Latin America. Geoforum. 2005;36(1):17-28.

4. Butler J. Gender Trouble. New York: Routledge; 1990. 92 p.

5. Lyons L. Disrupting the Centre: Interrogating an 'Asian Feminist' Identity. Communal/Plural: Journal of Transnational \& Cross-Cultural Studies. 2000;8(1):65-79.

6. Collins PH. It's all in the family: Intersections of Gender, Race and Nation. In: Narayan U, Harding S, editors. Decentering the Center: Philosophy for a Multicultural, Postcolonial, and Feminist World. USA: Indiana University Press; 2000. pp. 156-176.
7. Grosz E. Bodies and Knowledges: Feminism and the Crisis of Reason. In: Alcoff L, Potter E. Feminist Epistemologies. New York: Routledge; 1933. pp. 187-215.

8. Williams JR. Doing feminist-demography. International Journal of Social Research Methodology. 2010;13(3):197-210.

9. Scott JW. The evidence of experience. Critical inquiry. 1991;17(4):773797.

10. Harding S. Gender, Development and Post-Enlightenment Philosophies of Science. In: Narayan U, Harding S, editors. Decentering the Center: Philosophy for a Multicultural, Postcolonial, and Feminist World. USA: Indiana University Press; 2000. pp. 240-261.

11. Spivak GC. Scattered speculations on the subaltern and the popular. Postcolonial studies. 2005;8(4): 475-486.

12. Hawkesworth M. Feminist Inquiry: From Political Conviction to Methodological Innovation. USA: Rutgers University Press; 2006. pp. 137-141.

13. Ackerly B, True J. Methods and Methodologies. In: Waylen G, Celis K, Kantola J, editors. Gender and Politics. Oxford: Oxford University Press; 2013. pp. 135-159.

14. Sylvester C. Feminist International Relations: An Unfinished Journey. UK: Cambridge University Press; 2002. 368 p.

15. May VM. Intersectionality. In: Orr CM, Braithwaite A, Lichtenstein D, editors. Rethinking Women's and Gender Studies. New York: Routledge; 2012. pp. 154-172.

16. Crenshaw K. Mapping the margins: Identity politics, intersectionality, and violence against women. Stanford Law Review. 1991;43(6):12411299.

17. Byrd JA, Rothberg M. Between subalternity and indigeneity: Critical categories for postcolonial studies. Interventions. 2011;13(1):1-12.

18. Bagheri N. Mapping women in Tehran's public spaces: a geo-visualization perspective. Gender, Place \& Culture. 2014;21(10):1285-1301.

19. Apodaca C. Overcoming obstacles in quantitative feminist research. Politics \& Gender. 2009;5(3):419-426.

20. Parisi L. The numbers do(n't) always ADD up: Dilemmas in using quantitative research methods in feminist IR scholarship. Politics \& Gender. 2009;5(3):410-419.

21. Bar On, Bat Ami. Marginality and Epistemic Privilege. In: Alcoff L, Potter E, editors. Feminist Epistemologies. New York: Routledge; 1933. pp. 83-100.

22. Spivak GC. Can the Subaltern Speak? In: Nelson C, Grosberg L, editors. Marxism and the Interpretation of Culture. Basingstoke: Macmillan Education; 1988. pp. 271-313.

23. Rose G. Situating knowledges: positionality, reflexivities and other tactics. Progress in human geography. 1977;21(3):305-320.

24. Haraway D. Situated knowledges: The science question in feminism and the privilege of partial perspective. Feminist studies. 1988;14(3):575599.

25. Cahill C. Including excluded perspectives in participatory action research. Design Studies. 2007;28(3):325-340.

26. Pain R. Social geography: on action-orientated research. Progress in Human Geography. 2003;27(5): 649-657.

27. De Vault ML. Liberating Method: Feminism and Social Research. USA: Temple University Press; 1999. 15 p. 